\title{
Innovation explosion catalysed by foresight-results of an experiment
}

\author{
Emmanuel G. Koukios ${ }^{1}$
}

Received: 15 August 2016 / Accepted: 17 November 2016/Published online: 24 November 2016

(C) The Author(s) 2016. This article is published with open access at Springerlink.com

\begin{abstract}
One of the major findings of the Greece-2021 Technology Foresight project concerns a multiple innovation blockage phenomenon, affecting strategic sectors of the national economy and society. To analyse and abate this predicament, the organisers of the end-ofproject Conference put together a game-like experiment, asking students and other participants to think innovatively by answering the question "in how many ways can you peel an apple?". The surprising results have verified the expectations from the test. The list of the more than 100 replies received is dominated by very innovative, especially mid-to-high-tech $(50 \%)$, as well as unconventional, such as lateral thinking (10-20\%) ones, whereas the low-to-mid tech responses (less than $1 / 3$ of the total) appear to cover functional niches. The results are assessed with the help of a transpersonal psychology model distinguishing three levels of intelligence; foresight acts at all three levels, but with priority on the highest level, where cultural, ethical and other valuesetting issues are determined.
\end{abstract}

Keywords Technology foresight $\cdot$ Innovation · Experiment · Policy · Greece

Emmanuel G. Koukios

koukios@chemeng.ntua.gr

1 Bioresource Technology Unit, National Technical University of Athens, NTUA Zografou Campus, GR-15700 Athens, Greece

\section{Introduction}

\section{Foresight frame}

The Greek Foresight exercise (in short hereafter, Greece2021) was a major future-oriented activity supported by the General Secretariat of Research and Technology (GSRT) and the European Commission. It had the aim to explore the roles Science, Technology and Innovation could play to determine the Knowledge Economy and Society pathways of the country; its time horizon was set at 2021 , i.e., the bicentennial of the Greek State which was established following the Revolution of 1821 [1].

The foresight approach used in the project consisted in the identification of drivers and barriers for long-term (1520 years ahead) change, which was followed by the construction of micro-scenarios, by 20 panels of experts and stakeholders, covering the major sectors of the Greek economy and society. The synthesis of the results of this, bottomwork led to the construction of 4 macro-scenarios by the project coordinators.

\section{Innovation blocked}

A key finding of the Greece-2021 exercise has been the identification of a kind of power "blockage" of the national innovation potential in a low-to-mid tech "trap." This particularly identified barrier mechanism was found to characterize especially the strategic "backbone" of the national economy, i.e. the sectors of agriculture, industry, and tourism, generating together more than $1 / 3$ of the GDP and the total employment, and affecting the future of the whole national economy and society. 
The use of the "trap" concept in this case signifies that, although the particular sectors face problems that could be solved by socio-technical changes, including innovation, the latter factors appear to operate as obstacles rather than drivers. For example, in the case of agriculture, research and development are considered as production costs, squeezing the profit margins of the farmers. In a similar manner, industry and tourism seem to be trapped in their favourite costminimizing strategies. Thus, research- and innovation-based development options end up as of low priority among key socio-economic actors [2].

\section{Student catalyst}

All these and other Greece-2021 findings were discussed during the 3-day End-of-Project Conference, which took place in the appropriately inspirational venue of the Athens Planetarium, and was attended by more than 300 persons, a balanced combination of researchers, stakeholders and other players, including a large group of more than 50 engineering students from the National Technical University of Athens.

The presence of students, together with that of some of their professors, fuelled the idea that they represent the future generation that will have to live and work through the period surveyed by the Greece-2021 Foresight exercise.

These thoughts in turn catalysed a game-like, innovation de-blocking experiment run by the project leaders: a competition among all conference participants with the theme: In how many ways can you peel an apple? or the Apple Peeling Test. The unexpected, to a great extent, results of this experiment will be reported and discussed in the following, with a view of learning a lesson useful for the national innovation policy and strategy.

\section{Methodology}

\section{Literature review synopsis}

The literature on the relationships between Foresight and innovation is long and variable, depending on the aspect examined. Recently, the catalytic role of Foresight on creativity was recognized [3], and the need for more experimentation has been noted [4]. On the other hand, the future role of universities as innovation locomotives is of concern [5], and the future implications for innovation policies have to be closely monitored, at both the national [6] level, and the European one [7].

\section{Apple peeling experiment}

The terms of reference of the experiment were first announced, orally and with a handout, to the conference participants during the Sunday afternoon opening session of the event, and were then repeated during all subsequent sessions. These "rules of the game" are presented in the following Box 1:

\section{BOX 1}

HARVESTING THE FRUITS OF THE "GARDEN OF GNOSIS" [3], and THE TEST OF APPLE PEELING

In how many ways can we peel an apple? Try to list as many as possible in the space provided below, including both Low and High Tech! Unconventional solutions are also welcome. Do not take into consideration any constraints (e.g., economic, nutritional, cultural). Please, hand in your filled-in form to the Workshop Secretariat the latest by Tuesday, 22/3,09.30 am. The results will be announced at the end of the Tuesday morning Plenary Session (11.00 am); the winners will be honored during the "Delphi Experience" (see Conference Programme). GOOD LUCK!

Both, individuals and groups were encouraged to compete and, as set in the announcement, there were no other rules restricting the innovatory spirit, e.g. economic, or other types of optimisation. The deadline was at the time of the end-ofconference excursion at Delphi, the archetypical location of future-oriented actions. The awards were to be offered to the winners at Delphi, in a symbolic gesture of recognizing and promoting future-oriented thinking.

\section{A triple blockage phenomenon}

According to the detailed findings of the Greek Foresight project, the blockage effects on innovation appear to be of three types, as already mentioned in the introduction (1.2) and summarised in Fig. 1:

- A low-tech barrier; consisting of a preference in looking for low-to-mid tech solutions;

- An inertia barrier, consisting of an underestimation of research as change factor; and

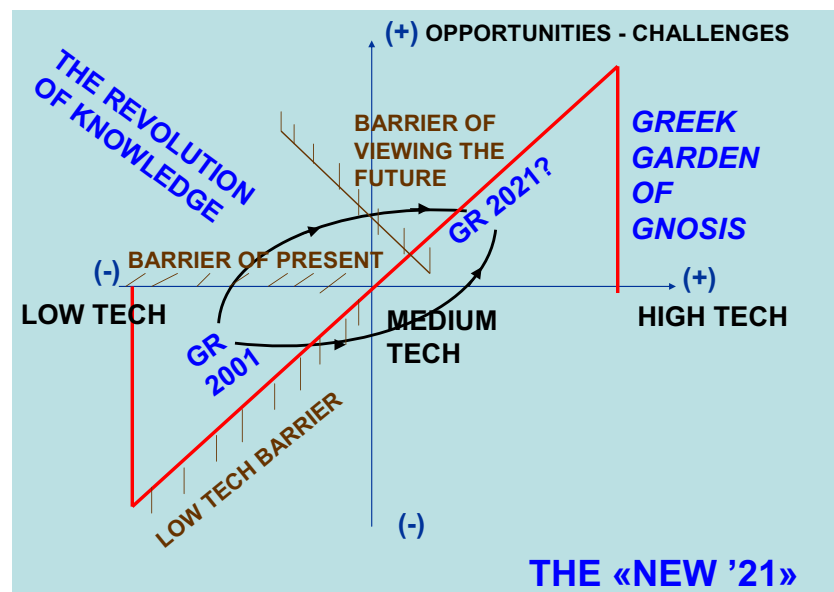

Fig. 1 The triple blocking effect on innovation identified by Greece2021 project [1] 
- A horizon barrier of viewing the future, consisting of an endemic "fear of the future."

All three obstacles will have to be overcome for Greece to reach its "Garden of Gnosis" - i.e., the vision-like best scenario - by 2021.

\section{Understanding innovation dynamics}

The findings of the Apple Peeling Test will be analysed with the help of a conceptual model for innovation based on the principles of transpersonal psychology. This school integrates various psychological and other approaches, e.g., transcendent, aspects of human experience. In its view, "the sense of the individual extends beyond conventional, personal or individual levels in order to encompass wider aspects of humankind and the cosmos" [8]. According to this school of thought, there exist three types and levels of intelligence, affecting awareness, consciousness and innovative activities, each having its own separate neural connection system: (I) rational - analytical - quantitative; (II) emotional - qualitative - behaviour determining; and (III) cultural - ethical spiritual - value-setting [9].

Our analysis has shown that the three types of innovation obstacles identified by the Greece-2021 Foresight exercise (see above, and Fig. 1) correspond rather well to a blocking of each of the three types of intelligence postulated by transpersonal psychology; a fact which could explain the acute form of the phenomenon for Greece, as each blocking mechanism tends to reinforce the other two, leading to a total "paralysis" of the innovation tendency.

\section{Results and discussion}

\section{Innovation explosion}

The results obtained practically overnight surprised everybody - and continue to surprise their readers until today and showed the way to a more systematic analysis of the innovative performance patterns related to Foresight. In a nutshell: more than 100 different ways to peel the proverbial and the real apple were recorded.

Specifically, we collected responses from ca. $10 \%$ of the conference participants; respondents were $70 \%$ male and $30 \%$ female. About $40 \%$ of the responses came from students (three-times their share by numbers), with the rest of responses being shared almost equally between persons employed in public $(30 \%)$ and private $(30 \%)$ sectors.

More than 300 answers were received in total (including duplicate or multiple replies). After analysis, 101 independent solutions were selected for reporting (see detailed lists in Tab. 1 ), grouped in the following 5 main categories according to the type of solution (in parenthesis, the number of solutions retained for reporting): (a) Mechanical (24); (b) Other Physical (24); (c) Chemical (21); (d) Biological (15); and (e) Unconventional (17).

0The three "Great Winners" of the test, based on the number of total (non-evaluated) solutions they have provided, are the following:

(A) Group of 5 collaborating students (National Technical U. of Athens): 116 solutions

(B) Dr. AH (Hungary), Member of Greece-2021 International Advisory Board: 55 solutions

(C) Mr. EA (Greece): 35 solutions

These best competitors, individuals and group, were awarded with special prizes during the Conference farewell dinner, in Delphi, offered by the Mayor of Delphi.

\section{Beyond high tech}

By analyzing the detailed results in Table 1, we can see that the Knowledge Community of the Foresight exercise has successfully escaped the low-tech trap, as

- More of $50 \%$, i.e. the majority of the replies describe midto-high tech solutions;

- $\quad 10-20 \%$ of the answers represent extremely innovative answers that could activate more innovation by lateral thinking;

- Less than $1 / 3$ of the solutions can be classified as low-tomid tech, but even them are placed in a totally different landscape, i.e., in close relation to other approaches.

The following solutions - one in each category - got a "Special Mention" by the organisers:

- MECHANICAL: Open a small hole all the way to the centre of the apple, and then, somehow, "turn the fruit inside out", so that the flesh becomes the new outside, with the peel taking the place of the new inside.

- OTHER PHYSICAL: Build a nano-machine, consisting of nano-tubes which selectively "transport" the fruit flesh material out, leaving the peel intact, and operating with solar power.

- CHEMICAL: Develop intelligent chemistry for selectively breaking the chemical bonds holding the peel on the fruit, under ecologically soft conditions.

- BIOLOGICAL: Use artificial molecular bio-intelligence, i.e., a bio-info-nano development of a bio-chip to be introduced in the apple tree life and take care of the whole peeling affair.

- UNCONVENTIONAL: Apply the topological paradox "Banach - Tarski", according to which, if the apple becomes infinitely big or small, then the problem is automatically solved. 
Table 1 Detailed results of the Apple Peeling Test

\begin{tabular}{|c|c|c|c|c|}
\hline Mechanical & Other Physical & Chemical & Biological & Out-of-the-box \\
\hline 1. Knife & 1. Pressure & 1. Water (boiling) & 1. Enzymes & 1. No peeling! \\
\hline 2. Knife \& fork & 2. Air & 2. Steam & 2. Microbial pulp & 2. No apples for all \\
\hline 3. Razor & 3. Deep freezing & 3. Acids & conversion & 3. Let somebody else do it \\
\hline 4. Scissors & 4. Heating & 4. Alkalis & 3. Microbial peel & 4. Delegate to a \\
\hline 5. Nail-cutter & 5. Fluidization & 5. Salts & conversion & bureaucrat \\
\hline 6. File & 6. Electricity & 6. Baking & 4. Consumption by birds & 5. We paint it \\
\hline 7. Other sharp tools & 7. Ball-mill - Other types of & 7. Barbecue & 5. Consumption by rodents & 6. We imagine it \\
\hline 8. Metal rubbing & milling & 8. Frying & 6. Special insects & 7. By telepathy \\
\hline 9. Medical tools & 8. Adsorption & 9. Controlled combustion & 7. Hormone injection & 8. By faith-religion \\
\hline 10. Surface rubbing & 9. Sand-blowing & 10. Catalysis & 8. No-peel fruit by genetic & 9. Virtual Reality - \\
\hline 11. By hand \& nails & 10. Fan & 11. Electrochemistry & eng. & Animation \\
\hline 12. Mouth and teeth & 11. Other vortex & 12. Oxidation & 9. Edible peel by genetic & 10. Topological model \\
\hline 13. Manual peeler machine & 12. Special Robots & 13. Chlorination & eng. & 11. Mathematics \\
\hline 14. Automatic peeler machine & 13. Microparticles & 14. Photochemistry & 10. Easy to peel fruit by & 12. Use of computer \\
\hline 15. Cutting in pieces & 14. Microwaves & 15. Radiochemistry & genetic eng. & virus/antivirus \\
\hline 16. Pulping fruit & 15. Ultra sound & 16. Special chemical cream & 11. After fruit rots & $($ apple $=$ file $)$ \\
\hline 17. Juice-making & 16. Laser & 17. Organic solvent & 12. Bio-magnetism & 13. Scanner - Erase by \\
\hline 18. Adhesive tapes & 17. Strong radiation & 18. Super-critical conditions & 13. Using the ecosystem & Paint Brush \\
\hline 19. Ceramic wheel & 18. Solar drying & 19. Plasma & 14. Improving human & 14. Lucky Luck: With his \\
\hline 20. Dentist tools & 19. Solarium & 20. Nano-tech degradation & digestion to assimilate & guns \\
\hline $\begin{array}{l}\text { 21. Emory polishing wheel } \\
\text { 22. Pulp remove by vacuum }\end{array}$ & $\begin{array}{l}\text { 20. Strong magnet (use of } \\
\text { metal particles) }\end{array}$ & & peel & $\begin{array}{l}\text { 15. Ninja: With their } \\
\text { swords }\end{array}$ \\
\hline 23. Spoon-eating pulp ... & $\begin{array}{l}\text { 21. Fall from height } \\
\text { 22. Carry on Formulal } \\
\text { /Rocket } \\
\text { 23. Anti-matter }\end{array}$ & & & $\begin{array}{l}\text { 16. Use apple as ball in } \\
4 \mathrm{X} 4 \text { football game }\end{array}$ \\
\hline SPECIAL MENTION & SPECIAL MENTION & SPECIAL MENTION & SPECIAL MENTION & SPECIAL MENTION \\
\hline $\begin{array}{l}\text { 24. Opening a hole to the centre } \\
\text { - turning fruit inside-out }\end{array}$ & $\begin{array}{l}\text { 24. Nano-tubes for selective } \\
\text { removal and use of pulp }\end{array}$ & $\begin{array}{l}\text { 21. Intelligent green chemical } \\
\text { lysis of peel-pulp bonds }\end{array}$ & $\begin{array}{l}\text { 15. Use of Artificial } \\
\text { Bto-Intelligence } \\
\text { (bio-info-nano) }\end{array}$ & $\begin{array}{l}\text { 17. Application of the } \\
\text { Banach - Tarski } \\
\text { paradox }\end{array}$ \\
\hline
\end{tabular}

\section{Unblocking innovation by foresight}

The surprising results of the Apple Peeling experiment were analysed with the help of the transpersonal psychology model already mentioned $[8,9]$, and assessed by brief interviews with some of the participants to explore the effects of this experiment on their life and careers. Particular emphasis was given to the effects of the Foresight frame and methodology on the outcome of the test. From the result, we can assume that the conditions of the experiment have removed all barriers and permitted an explosion of innovative thinking.

- The main de-blocking effect of Foresight as a frame of the whole action has been on the intelligence level (III), i.e. the one affecting basic norms and values; thus confirming the ideas about the priority of moral and spiritual factors in establishing a particular "culture," in this case, an innovation-oriented one [10]. This effect can be summarized in the phrase; "Innovation is a good thing!"

- This first effect opens to the way towards the creation of a community of persons governed by the same feelings and emotions, pursuing the same ideas, and orienting their behaviours to a few focal targets, thus easily overcoming the next barrier on intelligence level (II). This effect can be summarized by the phrase: "We want to innovate!"

- The last and final act of the innovation de-blocking process takes place at the intelligence level (I), where the available intellectual and analytical capacities can now deploy their excellence and make good use of their scientific expertise and rationality to overcome the last barrier and reach the targets already set at the previous two levels. This can be summarized by the phrase: "Let us use our knowledge in order to innovate!"

\section{Concluding remarks}

A number of potentially useful lessons for all the actors of the foresight process can be drawn from this experiment:

Lessons for innovation professionals : Foresight constitutes a potentially powerful mechanism, able not only to identify problems in the dynamics of innovation systems, but also play a catalytic role in repairing such systems, e.g. from innovation process blocks. In the case 
illustrated by the Apple Peeling experiment, the key steps of the Foresight-driven repair process were (i) strengthening an innovation culture, with strong values; (ii) establishing an emotionally stable community moved by common ideas; and (iii) activating skills and dexterities along well-defined axes.

Lessons for Greek policy makers: If the results of the apple-peeling experiment could be applied on a large scale in Greece, then the deployment of Foresight and other future-oriented practices could contribute in deblocking the national innovation system and promote beneficial technological and socio-economic development. Unfortunately this has not so far been attempted, mainly due to the financial crisis that had plagued this country for the last several years.

Lessons for Foresight practitioners: Running highcreativity research and innovation activities within broader Foresight exercises could be beneficial in many ways, such as to improve the quality of findings of the Foresight process and their socio-economic acceptance by the stakeholders and the general public. .

Acknowledgements A part of this work is based on the Greece-2021 Technology Foresight project supported by the General Secretariat of Research and Technology and the European Commission.

Open Access This article is distributed under the terms of the Creative Commons Attribution 4.0 International License (http:// creativecommons.org/licenses/by/4.0/), which permits unrestricted use, distribution, and reproduction in any medium, provided you give appropriate credit to the original author(s) and the source, provide a link to the Creative Commons license, and indicate if changes were made.

\section{References}

1. GSRT. Technology Foresight in Greece (2001-2021), Synthesis Report, Ministry of Development, Athens, 2005 (in Greek)

2. Agrafiotis D, Koukios E, Maroulis N (2014) Technology foresight in Greece - Synthesis report. In: Hletsos M, Agrafiotis D (eds) Scientific and technological foresight - Greece 2021. Pedio Publishers, Athens, pp 21-169

3. De Brabandere L, Iny A (2010) Scenarios and creativity: thinking in new boxes. Technol Forecast Soc Chang 77:1506-1512

4. Cuhls K, Daheim C (2016) Introduction to the special issue on experiencing futures. Futures. doi:10.1016/j.futures.2016.09.004

5. Blass E, Hayward P (2014) Innovation in higher education: will there be a role for the 'academic university' in 2025? Eur J Future Res 2:41. doi:10.1007/s40309-014-0041-x

6. Weinberger N, Decker M, Fleischer T, Schippl J (2013) A new monitoring process of future topics for innovation and technological analysis: informing Germany's innovation policy. Eur J Future Res 1:23. doi:10.1007/s40309-013-0023-4

7. Burgelman J, Chloupkova J, Wobbe W (2014) Foresight in support of European research and innovation policies. Eur J Future Res 2: 55. doi:10.1007/s40309-014-0055-4

8. Bynum EB (1992) A brief overview of transpersonal psychology. Humanist Psychol 20:2-3

9. Shiv B (2012) What is the Path to Increased Innovation? Stanford Business School Insights, Auguste 16, 2012

10. Steare R (2006) Ethicabililty: how to decide what's right and find the courage to do it. Roger Steare Consulting Ltd 